\section{Viewpoint}

In the world of science, EPS emerges and, just as surely as the growing plants, it requires nurture and attention if it is to blossom and bear fruit. Structurally, EPS has a constitution which assures it of support both from national societies and from Individual Ordinary Members and Associate Members. However, EPS has two basic requirements - sound financial sources and an effective medium for communication - both of which require commitment from EPS members of all categories.

This page holds an article by O. G. Folberth, Chairman of the Advisory Committee of EPS on Applied Physics and Physics in Industry. He reviews the results of the survey which investigated how EPS might increase the number of its Associate Members (or sound financial sources). This article forms a basis for discussion for the business meeting with Associate Members at the EPS General Conference in Wiesbaden on 4 October 1972 (see page 4).

To strengthen the EPS medium of communication, national societies and EPS Divisions have been invited to appoint correspondents to Europhysics News. In addition, Individual Ordinary Members and Associate Members are encouraged to submit articles and letters (see page 7 for notes).

With its two fundamental needs so satisfied, EPS has real potential for growth into a strong, virile and influential body producing beautiful flowers and succulent fruits for the world of science.

\section{Contents}

Viewpoint . . . . . . . 1

EPS and Industry . . . . 1

Wiesbaden progress . . . 4

Society news. . . . . . 6

Writing for

Europhysics News . . . 7

Meetings

\title{
EPS and its Relations with Industry
}

\section{Results of a European Inquiry}

\section{O.G. Folberth}

In a previous issue of Europhysics News (2 (2) March 1971), the relations of EPS with industry were discussed with special reference to Associate Membership. Under this category, appropriate industrial companies and other corporate bodies, not qualified to join as Members under Article $4 \mathrm{~b}$, may take their place within EPS. The same issue featured a pull-out questionnaire inviting all European physicists to provide guidance on the kind of services which present and prospective Associate Members might find attractive and useful. In this issue of Europhysics News, the author, helped by two of his colleagues from the Advisory Committee on Applied Physics and Physics in Industry, presents an evaluation of the response to the questionnaire. Although this evaluation is not devoid of personal, and therefore controversial, judgment, it nevertheless represents essentially the general opinion of the Advisory Committee. Moreover, it is hoped that the present article will stimulate additional comments on the consolidation of relations between EPS and industry, perhaps in the form of 'Letters to the Editor', and will serve as a 'curtain-raiser' to a business meeting with the Associate Members themselves on the occasion of the EPS General Conference in Wiesbaden on 4 October 1972.

\section{Overall response}

By the end of 1971, the Main Secretariat had received 645 questionnaires of which only some $10 \%$ were returned anonymously. This total may seem small in relation to the Europhysics News circulation of over 30,000 copies, but it is not inconsistent with general experience with pull-out, rather than personally-addressed, questionnaires, especially if allowance is made for the concentration of replies from certain countries (Table 1).

Table 1 Distribution of respondents by country

$\begin{array}{lr}\text { Great Britain } & 170 \\ \text { Fed. Rep. Germany } & 142 \\ \text { The Netherlands } & 68 \\ \text { France } & 47 \\ \text { Switzerland } & 36 \\ \text { Belgium } & 26 \\ \text { USA } & 22 \\ \text { Italy } & 18 \\ \text { Norway } & 15 \\ \text { Other countries (14) } & 54 \\ \text { Not identified } & 47 \\ & \\ \text { Total } & \end{array}$

The above breakdown reflects the traditionally close ties between the national physical societies and industry in Great Britain, Fed. Rep. Germany and The Netherlands. The high participation rate from Switzerland and Belgium may be ascribed, at least in part, to the presence in these countries of international organisations such as CERN and the EEC establishments. The few replies from Eastern Europe countries may reflect different employment and organisational patterns for physicists. 
Although the inquiry, by its nature, relates closely to industry, the replies from the industrial sector were, in fact, somewhat fewer than from those located at universities and other teaching establishments (Table 2). Similarly, Table 3 shows that pure research was the largest category of employment, although in this context it has to be remembered that respondents were free to indicate more than one activity if they so wished.

\section{Table 2 Location of respondents}

\begin{tabular}{lr}
\hline Universities/Teaching & 256 \\
Industry & 235 \\
Government & 124 \\
Others & 30 \\
(including not identified) &
\end{tabular}

Total

\section{Table 3} Work of respondents

Pure Research 314

Applied Research

280

Teaching

Administration

269

Development

Patents

Production

Marketing

Publishing

Other

Not identified

146

It is encouraging to see that there have been a useful number of replies from physicists engaged in fringe fields such as patents, marketing and publishing, and a strong body of replies from administrators.

\section{Services to Associate Members}

The main part of the questionnaire put forward, under questions 5.a) to 5.f), six proposals for services aimed at the expansion of relations between EPS and its present and potential Associate Members. Recipients were invited to express views for or against each proposal (or to abstain if they had no particular opinion), and the resulting analysis of all replies is given in the main table of this article (Table 4). The percentage voting for each proposal is given in the column headed 'popularity'; similarly for 'abstentions' and against'. 'However, in addition, most recipients took advantage of the invitation to rank the proposals which they favoured in order of priority. Accordingly the column headed 'priority' gives the percentage of those favouring a particular service who also accorded it high priority.

The reader may draw his own deductions from Table 4, but the
Advisory Committee has been further assisted in many instances by written comments which threw additional light on the voting and which raised new points. It is also important to allow for human nature, and to recognise that a proportion of the replies to the questionnaire were coloured by what the respondent would himself like in the way of services. Such subjective information is valuable and instructive in the development of EPS, but is not necessarily consistent with what will most attract and maintain the interest of Associate Members in EPS activities. Partly to correct this, a selection was made of 72 senior physicists in or close to industry, who are likely to be in a position to influence the relation of corporate bodies with EPS, and their replies separately analysed. The divergences from the overall percentages shown by this group are given in parentheses in Table 4. Although, for reasons of space, the figures are not reproduced here, similar divergences were extracted for other groups of physicists from common fields of activity, as will be indicated later.

The first service, 5.a), concerned the provision of information about conferences organised or sponsored by EPS with which are associated symposia on applications, or workshop discussions having particular regard to the needs of industry. Clearly this proposal is generally welcome, with relatively high, but not top, priority.

The proposal, 5.b), to draw up a European register of consultants expert in specific fields of physics who would be prepared to help Associate Members for a reasonable fee, is far less popular, and indeed controversial. In particular, many more industrial physicists voted against it. The objections may be on the grounds of practicability and/or because the need is not strongly recognised. However, those who did favour this service gave it considerable priority.

The holding of conferences specifically for Associate Members, as proposed under 5.c), seems quite well received and is given high priority. However this proposal, in particular, is very much a matter for discussion with Associate Members themselves. One Associate Member felt that it would be undesirable to hold such conferences in isolation; instead special sessions should be held on the occasion of ordinary EPS conferences.

As opposed to conferences specially arranged for Associate Members, the more modest service under 5.d) would inform them of post-doctoral and refresher courses likely to be of particular interest. Although quite popular, the supporters of this proposal give it low priority. However, rather than reflecting a negative attitude towards such courses, it may result from a general opinion that such courses on a European scale are not really needed, as they are more conveniently and effectively arranged on a local or national basis. This conclusion is supported by some of the written remarks.

The response to proposal 5.e) indicates that this is ranked lowest in popularity and priority. Nevertheless the on-cost involved in supplying at least a selection of EPS publications and reports to Associate Members, free of charge, would probably be relatively small and much depends on the views of the Associate Members themselves.

The final proposal, 5.f), relating to the temporary and two-way transfer of physicists between industrial and academic sectors in Europe is popular but-on closer analysis-controversial. In particular, the vote of senior industrial physicists against this proposal is very high compared with the overall figure, perhaps because of practical inhibitions rather than any disagreement with the potential value of such interchanges.

\section{Views of different groups}

The foregoing discussion of the overall response to questions 5. a) to 5.f) has included, where appropriate, any modified outlook from senior physicists in industry. However it is illuminating to consider other sub-sets of the replies received.

Firstly, those working in universities or other teaching-oriented institutions tend to show greater preference for 5.b), 5.d) and 5.f) ; these results suggest that they themselves are healthily interested in such activities. On the other hand there is, on the whole, a higher than average abstention rate which could reflect some detachment from, or uneasiness about, the inter-relation between industry and physics.

A somewhat similar, but less pronounced, tendency is shown by physicists in government-sponsored institutions. In addition there is an interesting and significant increase in the popularity and priority for $5 . f$ ) ; presumably government physicists would themselves welcome the stimulus of a personnel exchange scheme.

Apart from the group of senior industrial physicists mentioned previously, replies from 163 more junior 


\section{Service}

Popularity Priority

Abstentions Against

a) Providing direct information about conferences organized or sponsored by EPS with which symposia on applications or workshop discussions having particular regard to the needs of industry are associated.

$85(+11) \quad 24(+12) \quad 7 \quad(-7) \quad 8 \quad(-4)$

b) Provision of a European register of consultants who are experts in specific fields of physics and would be prepared to provide help (for a reasonable fee) on request from Associate Members

$72(-3) \quad 24 \quad(-5) \quad 8 \quad(-7) \quad 20(+10))$

c) Organization of annual conferences to meet the specific needs of Associate Members. At these conferences carefully selected speakers would present up-to-date reports in selected fields of physics with a high potential for industrial applications. Such annual conferences would also enable EPS to provide direct information on the scope of its activities and would facilitate the exchange of ideas between Associate Members drawn from a wide range of different enterprises and environments

\begin{tabular}{|c|c|c|c|}
\hline 77 & $(+2)$ & $32(+11)$ & 7 \\
\hline
\end{tabular}

d) Information on post-doctoral and refresher courses of particular interest to Associate Members.

$\begin{array}{llllll}76 & (-9) \quad 11 \quad(-3) \quad 7 \quad(-4) \quad 17(+13)\end{array}$

e) Receipt, free of charge, of all EPS publications and reports including those issued on behalf of the Specialized Divisions and the Advisory Committees.

$47(+9)$ $6(+3)$ $12(-5)$ $41(-4)$

f) A scheme for the exchange of personnel, to arrange for and to facilitate the temporary transfer of physicists in Europe from industry to academic institutions and vice-versa. . . $83(-18) \quad 39(-18) \quad 5 \quad(-3) \quad 12(+21)$

Note: The figures in parentheses are the divergences from the overall percentages shown by a selected group of 72 senior physicists in industry. The total number of respondents was the base of 645 .

and younger physicists in industry were also analysed. The divergences from the overall popularity figures are all in the opposite sense to those of the university/teaching group. Again personal preference presumably plays a strong role. Refresher courses are less popular, but those who want them accord them higher priority.

\section{Written remarks}

Two of the remaining three questions asked for suggestions for other services, question 6 , and for any comments of useful guidance, question 8 . The answers to question 7 , relating to the size of company most likely to be helped by the services proposed under question 5 , did not yield any meaningful conclusion, except perhaps that the question should have been phrased in terms of type of business rather than size.

The total number of respondents who made specific replies or suggestions concerning the questions 6 and 8 was 212 ; about 95 of these respondents were mainly engaged in such non-industrial activities as pure research, teaching or 'pure ' scientific publishing. The answers covered a considerable spectrum and the analysis which follows concentrates mainly on the well-supported requests and suggestions.

Better access to information on industry was the dominant theme of the largest group of comments (40 replies), the sub-divisions of this group being :

Those who wanted to know more about the problems of industry (31) ; presumably technical problems are implied, but the replies were not sufficiently specific to be certain that other industrial problems were excluded.

Those who wished to participate in working visits to industry (9).

Of these replies, 34 came from nonindustrial organisations, out of a total of 95 people in such organisations who answered questions 6 and 8 .

Dissemination of technical information was the theme of 38 replies, broken down into :

Requests for a register of fields of activity of all types of European labrratories (11).
Requests for improved documentation sources (11) but for fewer conferences (8).

Requests for a European physics exhibition, possibly associated with a conference (8).

Personal exchange and an employment register were the theme of the third largest group of replies (31), various specific suggestions being :

that the EPS should promote the exchange of personnel between different countries or types of employer in Europe (15), and that the EPS should set up an employment register (12) or conduct a market survey into future requirements for physicists in Europe (4).

Concern with the environmental, military and sociological consequences of physics was expressed in 10 replies. A desire for a more multidisciplinary approach, e.g. through meetings with other scientific and engineering bodies was expressed in 9 replies. Miscellaneous replies ranged from such questions as procurement of surplus equipment to a recommendation that the EPS be wound up forthwith ! 
The dominant theme which appears to emerge from the answers to questions 6 and 8 seems to be a desire on the part of European physicists to broaden their knowledge and experience. This is further illustrated by the worthwhile topics mentioned by isolated individuals, such as the management of research and development, venture capital management in relation to physics, the international recognition and standardisation of diplomas and the comparison of university-industry relations between different European countries. Gratifyingly, if surprising, it was a few physicists from larger European countries who expressed the sentiment that EPS could supply the broader framework which individual European countries could not provide.

\section{Conclusion}

Both in regard to the more general written remarks and the voting on the services to Associate Members, it is clearly necessary to study more fully such questions as the extent to which the opinions expressed are representative of EPS as a whole; and moreover are directly applicable to the interests of Associate Members. The balance between the resources, including finance, needed to carry out the suggestions will clearly have to be weighed against the benefits likely to follow. Such further consideration will constitute a vital part on the immediate future activities of the Advisory Committee on Applied Physics and Physics in Industry. Moreover, before the Advisory Committee submits its recommendations to the Executive Committee, it will await the outcome of the business meeting with Associate Members at Wiesbaden to which reference was made in the introduction to this article.

\section{Optical spectroscopy of solids}

\section{Edited by B. Rosen}

and J. Depireux.

The Proceedings of the $X$ th European Congress on Molecular Spectroscopy, held in Liège in 1969 , are available under the above title.

Price : BF 500.-.

Société Royale des Sciences de Liège, avenue des Tilleuls 45, B-4000 Liège, Belgium.

\title{
EPS General Conference
}

\author{
Wiesbaden, 3-6 October 1972
}

\section{Theme: Trends in Physics}

On 3-6 October 1972 in Wiesbaden, FDR, EPS will hold its Second General Conference and an associated Physics Exhibition. The aims of the Conference and Exhibition were described in the last issue of Europhysics News (3 (1) January/February 1972), and this present article is a progress report.

The provisional programme is set out in full on the opposite page and contains details of the speakers at the plenary sessions in the mornings and evenings. Preliminary information on the sessions organized by EPS Divisions is given at the end of this introduction.

Invitations have been sent out to companies to inform them about the Physics Exhibition and about the Handbook in which they may publish advertisements. Associate Members will be entitled to claim $25 \%$ discount, both on exhibition space and on advertisements. Exhibitors will be able to publish details of their products and services in the Handbook.

In order to encourage the attendance of student physicists, 200 beds have been reserved in the youth hostel in Wiesbaden where bed and breakfast would be available for DM 6.50 per night. Several national societes have also been able to arrange special grants for students wishing to attend.

\section{General Assembly}

Wiesbaden, 4 October 1972

On Wednesday. 4 October 1972, at $15.30 \mathrm{hrs}$, the General Assembly of the European Physical Society will meet at Wiesbaden in ordinary session (following Article 12 of the Constitution), on the occasion of the Second EPS General Conference.

Individual Ordinary Members and Member Societies of EPS (one delegate per Society for the latter category) are invited and are urged to attend. During the meeting, reports will be presented by the President, the Secretary and the Treasurer on the development of EPS and on plans for the future. A discussion period will follow. Details of the Agenda will be announced at a later date.

To attend the Conference or to book space at the Physics Exhibition, please contact

\section{Mr. U. Dihle,}

Physikalisches Institut

der Universität,

Robert Mayer-Strasse 2-4,

D-6000 Frankfurt/Main, FDR.

(Telephone 7797 31).

\section{Divisional sessions}

ASTRONOMY AND ASTROPHYSICS

Gravitational waves D. Sciama

(Oxford, UK)

High energy astrophysics $K$. Pinkau

(Munich, FDR)

Infra-red astrophysics

P. Léna (Meudon, France)

Astrophysical aspects of highly collapsed

bodies F. Pacini (Frascati, Italy)

ASTRONOMY AND ASTROPHYSICS COMPUTATIONAL PHYSICS

\section{Spiral structure of galaxies}

F. Hohl (Hampton, USA)

Computing experiments on stellar systems

P. Bouvier (Geneva, Switzerland)

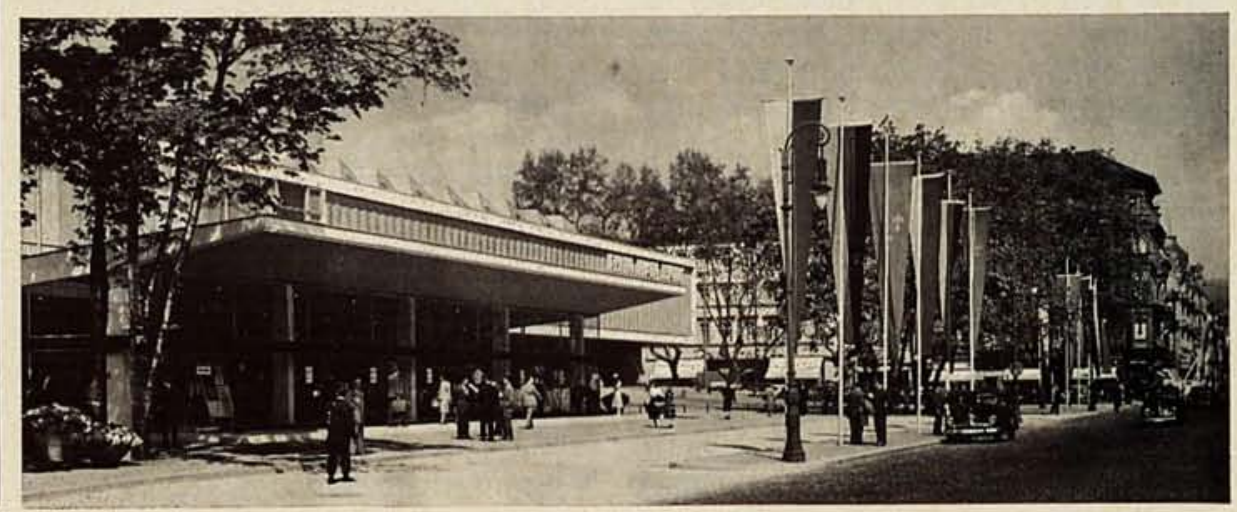

